\title{
KONSEP JUAL BELI ONLINE MENURUT PERSPEKTIF HUKUM ISLAM
}

\author{
Diah Syifaul A’yuni, Akhmad Sobrun Jamil, Khitnah Ummul Qori'ah \\ Institut Pesantren KH Abdul Chalim Mojokerto \\ Email: diah.ayuni87@gmail.com,sm_syahadah@yahoo.com, \\ khitnahummul17@gmail.com
}

\begin{abstract}
Along with the development of technology that creates innovation in sales, namely online sales. Make it easy for sellers to sell merchandise without having to bother opening a stall and arranging merchandise. Then make it easier for buyers to choose items with the desired criteria. And also facilitate buying and selling transactions according to the contract. This paper aims to see how the concept of buying and selling is online according to the perspective of Islamic law. The method used in this paper is a qualitative descriptive approach. Online sales have fulfilled the agreement contract according to sharia rules such as the existence of sellers, buyers and sighah. In buying and selling online has benefits from the seller's side, but there are some problems that must be minimized. So that sellers or buyers both benefit from buying and selling online.
\end{abstract}

Keywords: online trade, islamic law

\section{ABSTRAK}

Seiring dengan perkembangan teknologi yang menciptakan inovasi dalam penjualan yaitu penjualan online. Memudahkan penjual menjual barang dagangan tanpa harus bersusah paya membuka lapak dan menata dagangan. Kemudian memudahkan pembeli dalam memilih barang dengan kriteria yang diinginkan. Dan juga memudahkan transaksi jual beli sesuai akad. Tulisan ini bertujuan untuk melihat bagaimana konsep jual beli online menurut perspektif hukum islam. Metode yang digunakan dalam tulisan ini dengan pendekatan deskriptif kualitatif. penjualan online sudah memenuhi rukun akad menurut aturan syariah seperti, adanya penjual ,pembeli dan sighah. Dalam jual beli online memiliki manfaat dari sisi penjual, namun ada beberapa permasalahan yang harus diminimalisir. Agar penjual atau pembeli sama- sama diuntungkan dari jual beli melalui online.

Kata kunci: perdagangan online, hukum islam

\section{PENDAHULUAN}

Manusia merupakan makhluk sosial yang hidup bermasyarakat (Zoon Politicon). Manusia tidak hanya mengandalkan kekuatannya sendiri untuk mencukupi kebutuhan hidupnya tanpa bantuan dari orang lain. telah berabad-abad konsep manusia sebagai makhluk social itu menitik beratkan pada pengaruh masyarakat yang berkuasa kepada individu. Dimana unsur-unsur kehausan biologis yang salah satunya mncukupi 
kebutuhan makan sehari-hari. Salah satu cara manusia mencukupi kebutuhan tersebut adalah dengan melakukan kegiatan jual-beli (Muamalah).

Manusia senantiasa mengalami perkembangan dan perubahan sesuai kemajuan zaman. Allah menurunkan Al-Qu'ran untuk mengatur konsep jual-beli yang adil agar tercapai kesejahtraan bagi semua golongan. Hubungan manusia satu dengan manusia berkaitan dengan harta diatur agama islam salah satunya dalam jual beli. Jual beli yang didalamnya terdapat aturan-aturan yang seharusnya kita mengerti dan kita pahami. Jual beli seperti apakah yang dibenarkan oleh syara' dan jual beli manakah yang tidak diperbolehkan.

Ini sesuai dengan firman Allah SWT dalam QS al-Baqarah ayat 275

Artinya; "Padahal Allah telah menghalalkan jual beli dan mengharamkan riba."

Sebelum ditemukannya internet apabila seseorang ingin membeli barang orang itu harus mendatangi pelapak dan secara langsung bisa mengecek barang yang akan dibeli dan dari situlah terjadi tawar menawar sampai terjadilah kesepakatan serah terima barang dengan uang antara penjual dan pembeli. Proses jual beli konvensional ini juga dibahas dalam fiqih Muamalah yang mensyaratkan proses jual beli akan menjadi sah menurut islam apabila terdapat adanya sighat aqad (ijab qabul), mahallul aqd (barang), al-aqidain (pihak yang mlaksanakan akad, dan maudhu'ul aqd (tujuan akad).

Dalam sighad al-aqd (ijab qabul) dilakukan secara langsung baik melalui lisan ataupun perbuatan (fiil) yang menandakan adanya kerelaan dari kedua belah pihak dalam melakukan kegiatan jual beli, Mahallul aqd merupakan objek yang diperjual belikan secara nyata dan dapat dicek keadaannya secara langsung, al-aqidain merupakan pihak yang melaksanakan akad dalam jual-beli tersebut dan mempunyai sifat berakal, sehat, dewasa dan cukup memahami hukum dan maudhu'ul aqd at au tujuan adanya akad yaitu barang diterima oleh pembeli dan penjual mendapatkan keuntungan dari adanya akad tersebut.

Dari penjabaran diatas terdapat banyak perbedaan antara jual beli konvensional (secara langsung) dengan jual beli melalui media internet (online) dimana dalam proses jual-beli online tidak diperlukan adanya pertemuan antara penjual dan pembeli dan akad dilakukan tidak secara langsung melainkan melalui media. Dalam hal ini juga tidak bisa dipastikan barang yang akan dibeli itutersedia atau tidak, dan apabila tersedia pembeli 
tidak bisa mengecek kondisi barang yang akan dibeli karena kebanyakan penjual online lebih mengutamakan penjualan produk sebanyak-banyaknya dan lebih bahaya lagi bagi penjual yang tidak mengirimkan barang setelah uang pembelian ditransfer oleh konsumen. Dilain pihak penjual juga tidak bisa memastikan apakah konsumennya orang Mukhallaf (berakal, baligh, dewasa) atau tidak. Berdasarkan masalah yang terjadi diatas maka penulis ingin mengkaji ulang bagaimana hukum jual beli online menurut tinjauan hukum Islam (syara').

\section{JUAL BELI MENURUT ISLAM}

Pada dasarnya akad berasal dari kataal-'aqd dari bntuk masdar aqada dan dalam bntuk jamaknya adalah al-uqud yang memiliki arti perjanjian atau kontrak. Sedangkan arti akad menurut bahasa adalah pertalian yang mengikat. Adapun menurut Hasbi AshShiddiy mengartikan akad merupakan suatu keterikatan antara ijab dan Kabul dari kedua pihak natas rasa saling ridha diantara keduanya dan sah menurut hukum syara'. ${ }^{1}$

Ba'i (jual beli) menurut Sayid Sabiq secara bahasa adalah al-mudalah yaitu saling berukar sedangkan menurut istilah adalah berpindahnya kepemilikan melalui cara saling tukar menukar dengan adanya keridhoan pada masing-masing pihak. ${ }^{2}$ Imam Al-Thahawi, beliau merupakan ulama yang bermadzhab Hanafi yang mendefinisikan jual beli sebagai berikut:

$$
\begin{aligned}
& \text { وإذا تعاقد الرجلان البيع الجائزبينهما بلا خيار اشطرته فيه واحد منهما فليس لواحد منهما } \\
& \text { فسخه بعد ذلك تفرق بأبدائها عنموطن البيع أولم يتفرق }
\end{aligned}
$$

Imam an-nawawi yang merupakan ulama yang bermadzhab Asy-Syafi'i mempersingkat definisi jual beli; "pertukaran harta dengan harta atau sejenisnya dengan maksud untuk dimiliki. ${ }^{\prime 3}$

\footnotetext{
${ }^{1}$ Ariyadi, Jual Beli Online Ibnu Taimiyah, Yogyakarta: Diandra Kreatif 2018.

${ }^{2}$ Hasbiyallah, Sudah Syar'ikah Muamalahmu, Jakarta: Salma Idea 2014,

${ }^{3}$ Muhammad rizqi Romadhon, Jual Beli Online Menurut Madzhab Asy-Syafii, Tasikmalaya: Pustaka Cipasung 2015, Hlm 18
} 


\section{DASAR HUKUM JUAL BELI}

Pada dasarnya hukum transaksi jual beli adalah diperbolehkan, baik berdasarkan al-Qur'an dan Hadits ataupun dalam hukum Qiyas dan Ijma'. Dalam QS Al-Baqarah : 275 dijlaskan bahwa hukum transaksi jual beli sbagai brikut:

Artinya: Padahal allah telah menghalalkan jual beli dan mengharamkan riba...

Firman Allah dalam QS an-Nisa' : 29

$$
\text { ولاتقتلوأنفسكم إن الله كان بكم رحيما أذين أمنوا لا تأكلوا أمولكم بينكم بالبطل إلآ أن تكون تجرة عن تراض منكم }
$$

Hai orang-orang yang beriman, janganlah kamu saling memakan harta sesamamu dengan jalan bathil, kecuali dengan jalan perniagaan yangh berlaku dengansuka sama suka diantara kamu, dan janganlah kamu membunuh dirimuj sesungguhnya Allah adalah Maha Penyayang kepadamu. (QS. An-Nisa:29). ${ }^{4}$

Berdasarkan dalil diatas, Allah SWT memhalalkan transaksi jual beli atas keridhoan dari masing-masing pihak dan mengharamkan adanya riba. Karena riba merupakan salah satu tindakan yang sangat merugikan salah satu pihak dan allah mengharamkan prosvs jual beli yang dicampur dengan adanya unsur riba.

$$
\text { نهى رسول الله صلى الله عليه وسلم عن بيع الغرور (رواه مسلم) }
$$

Artinya: Rasulullah SAW Melarang jual beli yang didalamnya terdapat penipuan. (HR. Muslim)

Muhammad bin Ahmad al-syaitri menjelaskan dalam Syarh al-yaqt an-nafs

$$
\begin{aligned}
& \text { والعبرة في العقود لمعانيها لا لصور الألفاظ وعن البيع والشراء بواسطة التليفون والتلكس } \\
& \text { والبرقيات كل هذه الوسائلوأمثالها متمدة اليوم وعليها العمل }
\end{aligned}
$$

Yang diperhitungkan dalam akad-akad adalah subtansinya, bukan bentuk lafadnya. Dan jual beli via telepon, teleks dan telegram dan semisalnya telah menjadi alternatif utama dan dipraktikan.

Syihabuddin ar-Ramli dalam Nihayah al-Muhtaj ila Syarh al-Minhaj

\footnotetext{
${ }^{4}$ Shobirin 2015. Jual beli dalam pandangan Islam. E-journal vol. 3, no. 2.
} 


$$
\begin{aligned}
& \text { والأظهر أنه لا يصحّ في غير نحو الفقاع كما مرَّ (بيع الغائبِ)و هو ما لم يره } \\
& \text { المتعاقدان أو أحدهما ثمنا أومثمَّنا ولو كان حاضرًا في مجلس البيع وبالغا في وصفه أوسمعه } \\
& \text { بطريق التواتر كما يأتي أو رآه في ضَّوُء لوْنهُ كورِِ أبيضَ فيما يظهرُ }
\end{aligned}
$$

(dan menurut qaul al-Azhar, sungguh tidak sah) selain dalam masalah Fuqa', sari anggur yang dijual dalam kemasan rapat atau tidak terlihat (jual beli barang ghaib), yakni barang yang tidak terlihat orang kedua belah pihak yang bertransaksi atau salah satunya. Baik barang tersebut berstatus sebagai alat pembayar maupun barang yang dibayari. Meskipun barang tersebut ada dalam majlis akad dan telah disebutkan kriterianya secara detail atau sudah terkenal secara luas (mutawatir) seperti keterangan yang akan datang. Atau terlihat dibawah cahaya, jika cahaya tersebut menutupi warna aslinya, seperti kertas putih demikian menurut kajian yang kuat.

Pada refrensi dari Syihabuddin ar-Ramli, menjelaskan bahwa barang yang diperjual belikan diisyaratkan dapat dilihat secara langsung oleh kedua belah pihak. Hal ini merupakan bentuk kehati-hatian agar tidak terjadi kesalah pahaman pada kedua belah pihak dan terjaga dari bahaya gharar(penipuan) dalam transaksi jual beli khususnya jual beli online.

\section{SYARAT DAN RUKUN JUAL BELI}

Menurut Imam Nawawi dalam syarah kitab al-Muhadzab menjelaskan rukun dalam jual beli meliputi 3 syarat, yaitu adanya pihak yang melakukan akad (akid), barang atau obyek yang diakadkan (Ma'qud Alaihi) dan sighat atau bahasa yang digunakan untuk akad yang terdiri dai ijab (pnawaran) dan qabul (penerimaan) atas barang yang diakadkan. ${ }^{5}$

\section{MEKANISME JUAL BELI ONLINE MENURUT PERSPEKTIF HUKUM ISLAM}

Jual beli online merupakan kegiatan transaksi jual beli barang ataupun jasa yang sebagian besar prosesnya memanfaatkan layanan internet (feri sulianta,2015). ${ }^{6}$ dalam transaksi jual beli online pemilik toko hanya cukup mem-posting barang yang dijual

\footnotetext{
${ }^{5}$ Taqiyudin Abu Bakar, Kifayatul Akhyar(Cv Bina Iman,1995), Hlm 535

${ }^{6}$ Feri Sulianta. Kiat Dahsyat Membangun Usaha Online Dari Nol. Jakarta: Elex Media Komputindo 2015,
} 
dimedia social dan pembeli cukup melakukan transaksi melalui media chatting (pesan elektronik) dan apabila sudah tercapai kesepakatan kedua belah pihak tersebut maka barang dikirim melalui agen pengiriman barang ataupun dikirim langsung kapada konsumen (Cash On Delivery). ${ }^{7}$

Dalam jual beli online akad yang digunakan adalah akad salam. Akad salam adalah kesepakatan melakukan transaksi jual beli barang dimananjual hanya menyebutkan sifat barang yang dijualnya kemudian pembeli membayar terlebih dahulu harga barang yang dipesan sedangkan barang diserahkan setelahnya sesuai dengan kesepakatan dua belah pihak. ${ }^{8}$

\section{HUKUM JUAL BELI MELALUI MEDIA INTERNET}

Pada forum bathsul masail muktamar NU ke 32 dimakasar tahun 2010. Berisi tentang hukmum akad transaksi jual beli online dapat dikatakan sah apabila sebelum barang dan uang berpindah, kedua belah pihak sudah melihat mabi' (obyek yang diperjual belikan) atau telah disampaikan sifat maupun jenisnya. Serta memenuhi syarat dan rukun jual beli. ${ }^{9}$ Menurut Majmu' fiqh Islami dalam muktamar ke 6 di Jeddah memperbolekan melakukan transaksi jual beli melalui alat komunikasi modern. Hal ini dinilai sah sebagaimana transaksi yang dilakukan oleh dua orang dalam satu tempat asalkan transaksi tersebut memenuhi persyaratan sebagai berikut:

a. Adanya kejelasan pihak-pihak yang melakukan transaksi untuk meminimalisir resiko penipuan..

b. Tidak adanya pembatalan transaksi dari pihak ijab sebelum sampainya Kabul dari pihak kedua.

c. Alat transaksi benar-benar dilakukan oleh pihak yang bertransaksi (bukan orang lain). ${ }^{10}$

Perjanjian jual beli baik secara konvesional ataupun secara online dilindungi dalam Undang-Undang No.8 Tahun 1999 tentang perlindungan konsumen. Dalam

\footnotetext{
${ }^{7}$ Ahliwan Ardinata Dan Sunan Fanani 2015. Keridhaan Dalam Jual Beli Online. Unair E-Journal Vol. 2, No 1.

${ }^{8}$ Imron Rosyadi, Jaminan Kebendaan Berdasarkan Akad Syariah. Depok : Kencana 2017

${ }^{9}$ www.nu.or.id

${ }^{10}$ Hasbiyallah, Sudah Syar'ikah Muamalahmu, Jakarta: Salma Idea 2014, Hlm 12
} 
Undang-Undang tersebut mengatur tentang hak dan kewajiban para konsumen dan para pelaku usaha. Hak kewajiban konsumen dan mengenai pelanggaran dalam dunia maya ini pasal 9 Undang-Undang No. 11 Tahun 2008 Tentang Informasi dan Transaksi Elektrornik juga melarang penyebaran berita bohong dan menyesatkan yang mengakibatkan kerugian konsumen dalam transaksi elektronik, sebagaimana disebutkan dalam Pasal 28 ayat (1).

Dalam pasal 1320 KUHPerdata juga terdapat ketentuan aturan barang apa saja yang boleh diperdagangkan, dalam pasal tersebut suatu transaksi jual beli online bisa dikatakan sah menurut hak negara harus menepati persyaratan sebagai berikut:

a. Adanya kesepakatan antar pihak penjual dan pembeli dan tanpa adanya unsur paksaan

b. Kecakapan dari penjual, artinya penjual tersebut merupakan orang dewasa yang paham akan hukum di Indonesia.

c. Obyek atau benda yang diperjual belikan jelas wujudnya.

d. Adanya suatu sebab yang halal dan atas dasaran adanya I'tikad yang baik.

Dalam pasal 378 KUHPidana mengatur tindak pidana penipuan dengan rumusan pasal sebagai berikut:

"Barang siapa dengan maksud untuk menguntungkan diri sendiri atau orang lain secara melawan hukum dengan menggunakan nama palsu atau martabat (hoedaningheid) palsu dengan tipu muslihat ataupun rangkaian kebohongan, menggerakkan orang lain untuk menyerahkan barang sesuatu kepadanya atau supaya member utang maupun menghapuskan piutang. Diancam karena penipuan dengan pidana penjarapaling lama empat tahun."

Walaupun UU ITE tidak secara khusus mengatur mengenai tindak pidana penipuan, namun terkait dengan timbulnya kerugian konsumen dalam transaksi elektronik terdapat ketentuan dalam Pasal 28 ayat (1) UU ITE yang menyatakan :

"Setiap orang dengan sengaja dan tanpa hak menyebarkan berita bohong dan menyesatkan yang mengakibatkan kerugian konsumen dalam transaksi elektronik." 
Terhadap pelanggaran Pasal 28 ayat (1) UU ITE diancam pidana penjara paling lama enam tahun dan/atau denda paling banyak Rp 1 miliar, sesuai pengat uran pada pasal 45 ayat (2) UU ITE. ${ }^{11}$

\section{METODOLOGI PENELITIAN}

Pendekatan yang digunakan dalam penelitian ini adalah pendekatan deskriftif kualitatif. Dalam penelitian deskriftif kualitatif ini adalah penelitian lebih difokuskan pada penggunaan kajian studi pustaka melalui informasi dari buku, majalah, Koran dan literature lainnya untuk membentuk sebuah landasan teori (arikunto, 2006). Tujuan penelitian ini adalah menafsirkan dan menuturkan data yang terjadi pada masyarakat, dan apa pengaruh yang terjadi pada kondisi tersebut. Penelitian ioni juga bertujuan unt uk mentelaah jurnal ilmiyah, buku refrensi literature, ensiklopdia, karangan ilmiyah dan beserta sumber-sumber lainnya, baik dalam bentuk tulisan maupun format diginal yang relevan serta berhubungan dengan objek yang diteliti. Adapun yang menjadi objk dari kajian penelitian ini adalah tulisan yang menggambarkan bisnis usaha online shop yang sangat banyak berkembang di Indonesia.

\section{KESIMPULAN}

Hukum melakukan transaksi jual beli melalui media internet (online) pada dasarnya sah menurut syara', seperti halnya bertransaksi secara langsung. Dengan dapat memenuhi empat syarat sah jual beli dalam islam, yang pertama adanya Sighat Al- 'Aqd yaitu ijab dan Qabul yang tidah harus dilakukan secara langsung melainkan hanya dengan mngklik tombol OK pada akhir transaksi. Yang kedua adanya Mahallul 'Aqd yaitu obyek yang diperdagangkan nyata wujudnya dan dzatnya pada barang tidak melanggar aturan syarat sah jual beli (jelas kehalalannya). Yang ketiga Al-' Aqidain yaitu pihak yang melakukan transaksi haruslah dalam kategori Mukallaf (berakal, sehat, dewasa dan mengerti pada masalah hukum, yang diterapkan) dan syarat yang keempat Maudhu'ul 'aqd yaitu tercapai tujuan dari adanyajual beli tersebut yaitu pembeli membayar harga barang yang telah disetujui dan penjual segera mengirim barang yang

\footnotetext{
${ }^{11}$ www.hukumonline.com
} 
dipesan tanpa adanya unsur kecacatan, penipuan (tadlis ataupun tipu muslihat (taghir) dalam barang tersebut.

\section{SARAN}

1. Bagi penjual (merchant) dengan membuat form cara pemesanan barang, metode pembayaran, dan ketentuan pengiriman barang secara variatif. Dan penjual juga harus memastikan bahwa barang yang dikirim harus benarbenarr sampai pada tangan konsumen dan memastikan bahwa barang yang dikirim harus sesuai pada transaksi awal.

2. Bagi pembeli (Buyer). Harus lebih teliti terhadap dan berhati-hati terhadap penjual dan barang yang akan dipesan dan tidak terburu-buru dalam melakukan transaksi agar barang yang dipesan sesuai keinginan dan tidak melupakan melunasi harga barang yang dipesan sesuai kesepakatan awal.

\section{DAFTAR PUSTAKA}

Ardinata, Ahliwan. dan Sunan Fanani 2015. Keridhaan Dalam Jual Beli Online. Unair E-Journal Vol. 2, No 1.

Ariyadi, Jual Beli Online Ibnu Taimiyah, Yogyakarta: Diandra Kreatif. 2018.

Hasbiyallah, Sudah Syar'ikah Muamalahmu, Jakarta: Salma Idea 2014.

Bakar, Taqiyudin Abu. Kifayatul Akhyar. Cv Bina Iman. 1995.

Sulianta, Feri. Kiat Dahsyat Membangun Usaha Online Dari Nol. Jakarta: Elex Media. Komputindo. 2015.

Rosyadi, Imron. Jaminan Kebendaan Berdasarkan Akad Syariah. Depok: Kencana 2017

Romadhon, Muhammad rizqi. Jual Beli Online Menurut Madzhab Asy-Syafii, Tasikmalaya: Pustaka Cipasung 2015.

Shobirin 2015. Jual Beli Dalam Pandangan Islam. E-journal vol. 3, no. 2. www.nu.or.id 